\title{
Orientação de pais no processo de psicoterapia infantil de grupo
}

Parents' guidance in children group psychotherapy

Orientación de madres y padres en el proceso de psicoterapia infantil de grupo

\section{Helena Bazanelli Prebianchi*}

\begin{abstract}
Resumo
Este trabalho descreve um grupo de orientação de pais diferente daqueles cujo foco é o ensino de habilidades específicas de criação de filhos. Embora tais habilidades também sejam modeladas no grupo, o objetivo do trabalho descrito é ajudar os pais a abandonarem certos comportamentos negativos na criação de seus filhos, condutas fortemente ligadas à sua imagem pessoal e ao modo pelo qual foram criados. A condução do grupo de pais ocorreu concomitantemente ao atendimento terapêutico dos filhos. Na primeira etapa, os participantes aprenderam a identificar seus sentimentos negativos, ao mesmo tempo em que elaboravam princípios comportamentais e de desenvolvimento, na criação dos filhos. A segunda etapa da condução do grupo utilizou-se da dramatização e outras intervenções cognitivo-comportamentais para ajudar os pais a discriminarem seus sentimentos negativos anteriormente aprendidos, reduzindo a intensidade da culpa, da raiva, da vergonha e da autopiedade, possibilitando que reestruturassem os comportamentos em relação aos filhos.
\end{abstract}

Palavras-chave: orientação de pais; psicoterapia infantil; psicoterapia de grupo.

\begin{abstract}
This work describes a parent' guidance group which focus was different of those where the aim is teaching specific habilities in children' education. Although those habilities are also shapped by the group, the real focus of this work is to help parents to abandon their negative behaviors in relation to their children, on to its personal image and the way by which they had been created. The conduction of the group occurred concomitantly to the children psycotherapy. In the first stage, the parents had learned to identify their negative feelings and had implemented behavioral and development principles, in raising children. In the second stage, one
\end{abstract}

Doutora em Psicologia Profissão e Ciência pela Pontifícia Universidade Católica de Campinas, professora da Faculdade de Psicologia da Pontifícia Universidade Católica de Campinas. E-mail: helena@sigmanet.com.br. 
used role-playing and other cognitive-behavioral interventions to assist them to discriminate their negative feelings previously learned, reducing the guilt, the anger, the shame and the auto-mercy, making possible the reorganization of the behaviors in relation to the children

Key-words: group psychotherapy; child psychotherapy; parents'guidance group.

\section{Resumen}

Este trabajo describe un grupo de orientación de madres y padres distinto de aquellos cuyo foco es la enseñanza de capacidades específicas de crianza de hijos. Aunque tales capacidades también sean moldeadas en el grupo, el foco del trabajo descrito, es ayudar a las madres y a los padres a abandonar ciertos comportamientos negativos en la crianza de sus hijos, comportamientos fuertemente vinculados a su imagen personal y a la crianza que han tenido. La conducción del grupo de madres y padres ocurrió concomitante a la atención terapéutica de los hijos. En la primera etapa, los participantes aprendieron a identificar sus sentimientos negativos al mismo tiempo en que se imple-mentaban principios comportamentales y de desarrollo en la crianza de los hijos. En la segunda etapa de la conducción del grupo se utilizó el recurso de la dramatización y de otras intervenciones cognitivo-comportamentales para ayudar a las madres y a los padres a discriminar sus sentimientos negativos anteriormente aprendidos, reduciendo así, la intensidad de la culpabilidad, la cólera, la verguenza y la auto-piedad, haciendo posible que reorganizasen sus comportamientos en lo referente a sus hijos.

Palabras-clave: orientación de las madres y de los padres, psicoterapia infantil, psicoterapia de grupo.

\section{A} terapia comportamental infantil de grupo tem se mostrado como forma de atuação efetiva e importante no atendimento das necessidades das crianças encaminhadas às clínicas-escolas e ou aos serviços públicos de saúde (Prebianchi, 2004). Vários estudos, de fato, apontaram que a população infantil se constitui a clientela predominante nesses tipos de serviços.

A despeito dos possíveis equívocos verificados em boa parte dos encaminhamentos de crianças para serviços de saúde mental (Boarini, 1993; 1998; Silvares, 2000; Prebianchi, 2004), ainda é grande a demanda por atendimento psicoterápico infantil. Nesse sentido, a psicoterapia de grupo tem sido uma opção frequente de oferta de tratamento, tanto pelo seu valor 
em promover mudanças clinicamente significativas como também por apresentar-se como alternativa para colocar a psicologia clínica a serviço de um maior número de pacientes infantis, reduzindo o tempo em lista de espera e o período de tratamento.

Sob o enfoque behaviorista, o trabalho com grupos apresenta algumas vantagens: uma vez que, na psicoterapia, estratégias que favoreçam o contato direto com as contingências, na sessão, devem ser preferidas àquelas que apenas instruem sobre o comportamento adequado (Prebianchi, 2000), o grupo, ao simular o mundo real dos pacientes de forma mais acurada do que a situação dual da psicoterapia clássica, é um passo intermediário entre o desempenho de um comportamento recém-aprendido e a sua transferência para a comunidade (Rose, 1987). Como a maioria dos problemas clínicos é, em sua natureza, de interação social, a presença de outros fornece uma oportunidade de praticar novas habilidades sociais com companheiros num setting mais protegido. O grupo dá ao paciente a oportunidade de aprender e praticar muitos comportamentos, conforme ele responde às diversas e constantes demandas existentes: lidar com as idiossincrasias dos outros membros, oferecer feedback, dar conselho, reforçar os comportamentos dos companheiros.

Em última análise, o grupo é um laboratório natural para a aprendizagem do que é essencial às relaçôes sociais satisfatórias, enquanto oferece mais feedback sobre o quê, no comportamento do paciente, atrai ou afasta as pessoas (Corey, 2002).

Contudo, de acordo com concepções behavioristas, raras vezes, a psicoterapia da criança, seja ela do tipo individual ou de grupo, pode ocorrer isoladamente, prescindindo de um trabalho concomitante de orientação de pais. Isso porque se acredita que o comportamento de um membro da família depende da interação com outros membros (Wahler, 1975). Assim, se uma criança é considerada desviante, uma explicação desse desvio reside na interação com os outros membros. Os comportamentos deles contribuem para o desvio, e o comportamento desviante mantém os seus comportamentos.

Essa interdependência é vista em termos de estímulos reforçadores e discriminativos providos pelos vários comportamentos dos membros da família. O comportamento-problema da criança é visto como sendo controlado pelos reforços e estímulos discriminativos fornecidos por quem cuida da criança. Os comportamentos-problemas da criança são eventos-estímulos que controlam parcialmente as ações dos pais. As abordagens e reações dos pais operam como padrōes de dicas e reforçamento, determinando os comportamentos 
que a criança apresentará em casa. Os comportamentos da criança funcionam como dicas e reforços para os pais, e assim a contingência, ou melhor, os padrões de contingências dos pais são mantidos pela criança (Wahler, 1975). O comportamento da criança é diretamente mantido por cada um dos pais, e os comportamentos dos pais são multiplamente determinados.

De acordo com isso, tradicionalmente, um dos modelos de intervenção clínica e comportamental utilizados com crianças tem sido o modelo triádico. Neste, também chamado de manejo de contingências, há, pelo menos, três pessoas envolvidas no processo terapêutico: o terapeuta, o cliente e o mediador, que atua sob a orientação do clínico, com vistas à alteração do comportamento do cliente (Silvares, 1995).

Silvares (1995) afirmou que o modelo triádico sempre teve muita aceitação entre os terapeutas comportamentais infantis devido aos seus pressupostos básicos, a saber: a fim de que as mudanças comportamentais ocorram, os comportamentos inadequados não devem ser reforçados, ao contrário do que deve ocorrer em relação aos adequados, e são os mediadores que dispõem dos reforços a serem utilizados nas operações ambientais para promover as mudanças de comportamento.

Assim, o reconhecimento de que os pais podem se tornar agentes efetivos para a promoção de mudanças comportamentais em seus filhos tem resultado no desenvolvimento e avaliação empírica de numerosos programas de treinamento para pais, os quais, de um modo geral, focalizam o ensino de novas habilidades e ou trabalham para melhorar o relacionamento entre pais e filhos, fornecendo um modelo de interação (Stern, 2003).

Todas as considerações até aqui apresentadas têm determinado que parte do trabalho da autora, nos últimos anos, como supervisora dos alunos/estagiários de uma clínica-escola de Psicologia vinculada ao SUS, desenvolva-se de modo a oferecer terapia de grupo aos pacientes infantis e concomitante orientação de seus pais (também em grupo). No entanto, consonante o proposto por Stern (2003), a experiência com os pais das crianças atendidas revela que, embora, muitas vezes, estes pareçam estar receptivos a experimentar as estratégias comportamentais sugeridas no grupo, durante o transcorrer dos encontros, mostram-se incapazes de seguir as tarefas prescritas.

Alguns problemas específicos, como depressão dos pais, comportamento antissocial destes, muitos estressores e falta de apoio social, foram apontados, durante o processo de orientação de pais, como correlacionados com o baixo ganho ou falta de generalização (Horne \& Patterson, 1980; Griest \& Forehand, 1982). Wells (1981), ao abordar o encaminhamento de crianças 
para clínicas ambulatoriais, já indicara a influência do ajustamento dos pais ao dividir em três grupos as crianças encaminhadas: crianças comportamental e emocionalmente desviantes, cujas percepçôes dos pais são baseadas no comportamento atual das crianças; crianças desviantes, cuja percepção dos pais é também influenciada por seu próprio mau ajustamento; e crianças relativamente normais, cujas percepções dos pais não são adequadas e são baseadas em seu mau ajustamento pessoal, perda da tolerância ao estresse ou alto nível de aceitabilidade, mais do que sobre o comportamento atual da criança.

$\mathrm{Na}$ última década, alguns estudos têm sugerido que a criação de filhos pode ser melhorada, ajudando-se os pais a suavizarem a interferência de sentimentos negativos, como culpa, vergonha e autopiedade (Stern, 2003; Joyce, 1995; Nixon \& Singer, 1993).

A constatação de que os pais, em grupos anteriores, não conseguiam seguir as orientações fornecidas no grupo durante os encontros evidenciavam sentimentos negativos, como raiva do filho (pela atribuição errônea das causas de seu comportamento), raiva do terapeuta (por não responsabilizar o filho pelo mau comportamento), culpa em relação ao filho (por não conseguirem ser bons pais), culpa em relação ao terapeuta e ao grupo (por não ter êxito em seguir as tarefas propostas) e vergonha (pelos sentimentos anteriores), motivou o desenvolvimento do trabalho aqui apresentado.

Foi realizado um processo de orientação de pais, concomitante à psicoterapia de grupo de seus filhos, sendo o principal foco do trabalho aumentar a motivação dos pais para mudar, ao ajudá-los a abandonar certos comportamentos negativos na criação de seus filhos, fortemente ligados à sua imagem pessoal e ao modo pelo qual foram criados. Apresenta-se, a seguir, a estrutura e a sequência dos encontros realizados. Sendo nosso objetivo, tão somente, caracterizar a nova proposta nos seus elementos particulares, não nos deteremos naqueles aspectos já tidos como inerentes ao papel do terapeuta no trabalho com grupos, como, por exemplo, a promoção da coesão do grupo, a facilitação da autorrevelação pela promoção de um ambiente de aceitação e respeito mútuos.

\section{Estrutura e funcionamento}

A indicação de seis crianças para a terapia de grupo utilizou os critérios de natureza da queixa (não atendimento de ordens dadas pelos pais e comportamento agressivo em relação a irmãos e companheiros) e faixa etária (6 anos e 7 meses a 8 anos e 2 meses). 
Os dois terapeutas responsáveis pelo atendimento do grupo infantil conduziram também o grupo de orientação de pais.

Antes da primeira sessão com as crianças, marcou-se um encontro com os pais, sendo que compareceram, além dos terapeutas, sete pessoas (um casal de pais, quatro mães e um pai). O comparecimento dos pais foi determinado pelas suas compatibilidades de horários, sendo que essa mesma frequência se manteve nos sete encontros subsequentes (número não previamente determinado), todos com duração de 90 minutos e que ocorreram com intervalo quinzenal, em dias distintos aos daqueles dos atendimentos de seus filhos.

\section{Primeira etapa}

\section{0 encontro}

Após a apresentação do grupo, os terapeutas esclareceram sobre os objetivos e o processo da terapia de grupo infantil e, a seguir, solicitaram aos pais que relatassem suas queixas em relação ao comportamento de seus filhos. Num segundo período, os terapeutas apresentaram as concepções comportamentais sobre a natureza aprendida do comportamento e a interdependência entre o comportamento da criança e daqueles com os quais convive, justificando, assim, a necessidade de orientação de pais. Estabeleceram-se, com o grupo, o horário e a frequência dos encontros, e, finalmente, os terapeutas solicitaram aos pais que, durante a semana seguinte, registrassem as ocorrências dos comportamentos-problemas dos filhos, indicando as situações nas quais haviam acontecido.

\section{$2^{\circ}$ encontro}

Os terapeutas iniciaram o encontro, apresentando os conceitos de reforçamento positivo e negativo e punição. A seguir, solicitaram aos pais que relatassem o que haviam registrado e envolveram o grupo na tarefa de identificar os episódios de punição, reforçamento positivo e negativo presentes nos relatos. Depois, terapeutas e participantes geraram alternativas em termos comportamentais para lidar com as situaçóes apresentadas. Foi enfatizado pelos terapeutas que os pais deveriam antecipar os problemas e estabelecer consequências comportamentais claras e adequadas antes de esses acontecerem, e que deveriam comunicar, claramente, essas consequências à criança. Nesse momento, os terapeutas pediram aos pais que não tentassem realizar as alternativas até receberem orientação nesse sentido, mas sim que 
escrevessem, antes do próximo encontro, quais eram os seus sentimentos durante as ocorrências dos comportamentos-problemas dos filhos.

\section{$3^{\circ}$ encontro}

Após o relato dos pais sobre novas ocorrências dos comportamentosproblemas dos filhos, no intervalo entre os encontros, os terapeutas listaram, numa lousa, os sentimentos apontados: raiva, falta de controle da situação e humilhação. A seguir, foram feitas, com cada pai, dramatizaçôes das situações difíceis com os filhos para que pudessem confirmar os sentimentos listados e ou acrescentar outros. Os pais foram incentivados a lembrar (sem necessariamente, relatar) quais outras situações, que não aquelas envolvendo seus filhos, provocavam em si sentimentos semelhantes. Foi solicitado que, em casa, escrevessem numa folha de papel, as semelhanças e diferenças entre suas reaçôes aos seus filhos e às outras situações nas quais experimentavam o mesmo sentimento. Finalmente, realizaram-se dramatizações da implantação de estratégias alternativas. Tais dramatizações tiveram a seguinte sequência: no início, um pai assumia o papel de filho, e outro pai, agindo de acordo com orientaçôes do terapeuta, desempenhava o papel de pai; em seguida, o pai que havia representado o filho, entrava no seu papel e usava algumas das estratégias que outros já haviam testado.

Os pais foram então orientados a realizar as estratégias dramatizadas.

\section{Segunda etapa}

\section{$4^{\circ}$ encontro}

Três pais relataram que as estratégias haviam sido eficazes; dois disseram não ter sido necessário o uso das estratégias, pois os filhos se comportaram adequadamente; dois pais referiram que as estratégias haviam funcionado parcialmente, isto é, somente por alguns dias. Os terapeutas analisaram os êxitos e os insucessos, apontando alternativas. Os terapeutas retomaram o assunto do encontro anterior (situações que causavam sentimentos semelhantes), questionando os pais sobre se haviam lembrado outras situações, semelhanças e diferenças. As respostas foram, na sua maioria, afirmativas, e então os terapeutas esclareceram como os sentimentos dos pais eram função tanto dos comportamentos dos filhos como de suas histórias anteriores de aprendizagem, apresentando o conceito de padrões de comportamento. Os terapeutas propuseram que fossem dramatizadas situações de conflito que os pais experimentaram com seus pais, quando crianças (no início, o pai no 
papel de seu pai, e outro membro do grupo, no papel de filho; depois, o contrário). Os terapeutas questionaram os pais sobre quais sentimentos haviam experimentado nos papéis de pai e filho. As respostas foram listadas na lousa: no papel de pai, os sentimentos foram de raiva, vergonha e mágoa; no papel de filho, foram de medo, rejeição e piedade ("dó").

\section{$5^{\circ}$ encontro}

Os terapeutas convidaram os pais a relatar o que haviam descoberto sobre os sentimentos que apresentavam nas situações de conflitos com os filhos. Um pai disse que descobriu agir com o seu filho como o próprio pai (cujo comportamento não aprovava) fizera (todos os demais concordaram que faziam como seus pais). Uma das mães disse que, com sua filha, agia como sua mãe em relação a ela, mas, com outras pessoas, sentia o mesmo medo que sentira quando filha. Um pai concordou que se sentia rejeitado pelos outros, tal como experimentava nas situaçôes de conflito com seu pai. Os terapeutas enfatizaram que, assim como eles haviam aprendido com seus pais, estes, provavelmente, aprenderam com os deles e, portanto, ninguém poderia ser responsabilizado. Os terapeutas então apresentaram noções sobre as fases do desenvolvimento infantil e o que esperar em cada uma delas. A seguir, foi solicitado aos pais que identificassem em que fase se encontrava o filho e o quanto as dificuldades no seu comportamento encontravam-se relacionadas à etapa do seu desenvolvimento. Ao final, os terapeutas pediram aos pais que, até o próximo encontro, tentassem escrever quais eram os sentimentos dos seus filhos nas situações de conflito, anteriores e posteriores à implementação das estratégias desenvolvidas na orientação de pais.

\section{$6^{\circ}$ encontro}

Os pais apresentaram os sentimentos os quais julgavam os filhos terem antes e depois das novas estratégias: raiva, medo, desprezo (antes) e raiva, segurança, respeito e "limite" (depois). Os terapeutas apontaram ser natural que as crianças reajam com frustração e raiva ao estabelecimento de limites, cabendo aos pais compreenderem e não tomarem como pessoal, o que os ajudaria a manterem-se no papel de pais e educadores, minimizando a influência dos seus sentimentos negativos aprendidos. Os terapeutas apresentaram, em seguida, instruçóes adaptadas das técnicas de autocontrole e inoculação do estresse (Meichenbaum, 1974), para que os pais não permanecessem focados nos seus sentimentos negativos nos momentos de negociações com os filhos. Nesse sentido, foram realizadas dramatizaçôes e, na sequência, os pais avaliaram a própria capacidade de não permanecerem focados nos seus sentimentos negativos. 


\section{0 encontro}

O último encontro foi uma oportunidade para os pais revisarem o que aprenderam e avaliarem se os objetivos pessoais com relação aos seus filhos foram atingidos. Nesse sentido, todos os pais fizeram uma avaliação positiva do processo de orientação e da terapia de seus filhos. Os terapeutas incentivaram os participantes a formularem metas para si mesmos como pais, para trabalharem no futuro e tentarem prever como farão para atingi-las, a fim de manter os ganhos obtidos.

\section{Discussão e conclusões}

As dificuldades pessoais dos pais, muitas vezes, têm se mostrado incompatíveis com a obtenção de resultados satisfatórios nos processos interventivos de orientação e treinamento dos quais eles participam, quer seja porque impossibilitam o desenvolvimento desses processos, quer porque comprometem a generalização dos benefícios obtidos. Além do encaminhamento desses pais para psicoterapia e outros serviços de cuidado emocional, pouco tem sido feito, durante a orientação, para abordar diretamente essas dificuldades.

No entanto, os encontros aqui narrados evidenciam que é possível oferecer cuidado emocional diferente de psicoterapia e, de forma compatível, com os objetivos de um programa de orientação de pais, cuja função é atender à concepção do modelo triádico de terapia comportamental infantil.

As tarefas de cuidado emocional propostas aos pais fundamentaramse na auto-observação e na consequente discriminação de contingências, possibilitando a reestruturação dos sentimentos de culpa, de vergonha e de raiva (em relação aos outros, aos filhos ou ao terapeuta); sentimentos negativos que, via de regra, são incompatíveis com o desenvolvimento de novas habilidades na criação de filhos. Julga-se importante salientar que, ao propor as tarefas e ao ouvir os relatos correspondentes, os terapeutas, em nenhum momento, questionaram a "racionalidade" dos sentimentos nem tampouco tentaram alterá-los. Os terapeutas comportaram-se de modo coerente com os seus objetivos de não transformar aquele processo de orientação de pais em alguma forma de psicoterapia e também de não intensificarem, mediante sua contestação no grupo, os referidos sentimentos negativos.

Os grupos cognitivo-comportamentais tradicionais de treinamento de pais geralmente correm o risco de intensificar a vergonha, a raiva e a autopiedade destes, por apresentá-las como uma oportunidade de não conseguir seguir os protocolos do grupo. 
Para alguns pais, aprender a identificar e a administrar os sentimentos negativos anteriormente aprendidos, que interferem na sua interação com seus filhos, é condição indispensável para utilizar adequadamente as estratégias comportamentais apresentadas num programa de orientação de pais.

O trabalho aqui apresentado sugere que novos modelos de orientação podem ser implantados, sem perder as características essenciais dessa espécie de tratamento, as quais sejam o desenvolvimento de habilidades específicas para a criação de filhos e a promoção de relacionamentos familiares satisfatórios. Os resultados obtidos indicam que conforme os pais praticaram um cuidado emocional pessoal, dentro do processo de orientação, foram capazes de reestruturarem os comportamentos indesejados dos filhos, enquanto implementaram estratégias comportamentais apropriadas. Nesse sentido, acreditamos que a sistematização do modelo apresentado é uma tarefa necessária, a fim de possibilitar novas pesquisas sobre o tema.

\section{Referências}

Boarini, M. L. (1993). Unidades básicas de saúde: uma extensão da escola pública? Tese de doutorado não publicada. Programa de Pós-graduação em Psicologia, Universidade de São Paulo, São Paulo.

Boarini, M. L. \& Borges, R. F. (1998). Demanda infantil por serviços de saúde mental: sinal de crise. Estudos de Psicologia, 3 (1), 83-108.

Corey, M. S. \& Corey, G. (2002). Groups-process and practice. Washington D. C.: Brooks/Cole.

Griest, D. L. \& Forehand, R. (1982). How can I get any parent training done with all these other problems going on?: the role of family variables in child behavior therapy. Child and Family Behavior Therapy, 41, 73-80.

Horne, A. M. \& Patterson, G. R. (1980). Working with parents of aggressive children. In: R. R. Abidin (Org.). Parent education and intervention handbook (pp. 159-184). Springfield: Charles C. Thomas.

Joyce, M. R. (1995). Emotional relief for parents: Is rational-emotive parent education effective? Journal of Rational-Emotive and Cognitive Behavior Therapy, 13, 55-75. 
Meichenbaum, D. (1974). Cognitive behavior modification. Morristown: Genral Learning Press.

Nixon, C. D. \& Singer, G. H. (1993). Group cognitive-behavioural treatment for excessive parental self-blame and guilt. American Journal of Mental Retardation, 97, 665-672.

Prebianchi, H. B. (2000). O contar história como técnica psicoterapêutica. Dissertação de mestrado não publicada. Programa de Pós-graduação em Psicologia, Pontifícia Universidade Católica de Campinas, Campinas, SP.

Prebianchi, H. B. (2004). Atenção psicológica à criança: compreensão de supervisores e funcionários de clínica-escola. Tese de doutorado não publicada. Programa de Pós-graduação em Psicologia, Pontifícia Universidade Católica de Campinas, Campinas, SP.

Rose, S. D. (1987). Group therapy: a behavioral approach. New York: PrenticeHall.

Silvares, E. F. M. S. (1995). O modelo triádico no contexto de terapia comportamental com famílias. Psicologia: teoria e pesquisa, 11 (3), 235-241.

Silvares, E. F. M. S. (2000). Invertendo o caminho tradicional do atendimento psicológico numa clínica-escola brasileira. Estudos de Psicologia, 5 (1), 149180.

Stern, J. (2003). Treinamento de Pais. In: J. R. White \& A. S. Freeman (Orgs.). Terapia cognitivo-comportamental em grupo para populaçôes e problemas especificos. (pp. 381-415). São Paulo: Roca.

Wahler, R. G. (1975). Some structural aspects of deviant child behavior. Journal of Applied Behavioral Analysis, 8 (1), 27-42.

Wells, K. C. (1981). Assessment of children in outpatient settings. In: M. Hersen \& A. S. Bellack (Orgs.). Behavioral Assessment - A Practical Handbook. (pp. 301-318). New York: Pergamon Press. 